\title{
ATTEMPTED INDUCTION OF CHIMAERISM IN SHEEP
}

\author{
ELEANOR PIGHILLS, * J. L. HANGOGK† AND J. G. HALL \\ A.R.C. Animal Breeding Research Organisation, Edinburgh 9
}

(Received 8th June 1968)

\begin{abstract}
Summary. Transfers were made to twenty-two ewes of pairs of sheep eggs which had been fused in vitro after mechanical removal of the zona pellucida. The zona pellucida of the sheep egg unlike that of the mouse egg could not be removed by pronase digestion. Single lambs were born to three ewes. Transferrin typing was used to identify the genotypes of the lambs.

The transferrin findings on one (still-born) lamb were in accord with expectations for a chimaeric lamb.
\end{abstract}

\section{INTRODUCTION}

The experiments described here were undertaken in conjunction with an experimental programme dealing with the problems of hybridization of sheep and goats. In particular, it was regarded as a preliminary to any future attempts at the production of sheep-goat chimaeras.

The first method for producing mouse chimaeras was developed by Tarkowski (1961). This involved mechanical removal of the zona pellucida, fusion of the eggs at room temperature and culture of adhering pairs to form a single blastocyst with subsequent transfer to a pseudopregnant recipient. Later, a simpler technique was developed by Mintz (1964) which included removal of the zona pellucida by pronase digestion and fusion of the eggs at $37^{\circ} \mathrm{C}$. It was decided to attempt induction of chimaerism in sheep using, as far as possible, Mintz's technique.

With this procedure it is essential that zona-free eggs should be able to survive in vitro for a sufficiently long period to ensure their fusion before transfer to a recipient. It is shown here that, following transfer, sheep eggs are capable of development to term after removal of the zona pellucida and in vitro culture for $24 \mathrm{hr}$.

\section{MATERIALS AND METHODS}

A preliminary experiment with mouse eggs was undertaken to select an adequate culture solution and to establish a routine in this laboratory for the procedures of fusion and culture of eggs. The culture medium chosen was

* Present address: Department of Zoology, University College of North Wales, Bangor.

$\uparrow$ Present address: Royal Veterinary College, London, N.W.1. 
Earles balanced salt solution supplemented with $25 \%$ of either neonatal calf serum or neonatal lamb serum. The sera were obtained by bleeding newborn, unsuckled calves, or from the cord blood of lambs delivered by Caesarian section. The serum, previously heat-treated at $60^{\circ} \mathrm{C}$ for $20 \mathrm{~min}$, was added to the Earles solution immediately before use. This medium was equilibrated at $\mathrm{pH} 7.2$ under $6 \% \mathrm{CO}_{2}$ in air at $37^{\circ} \mathrm{C}$. The ewes were Scottish Blackface and Welsh from the Organisation's flock. Donor ewes were run with raddled fertile males, recipients were run with vasectomized rams and the ewes were examined daily for evidence of heat. Donor ewes were injected subcutaneously with mare serum gonadotrophin (PMSG) on Day 13. Welsh ewes received 750 i.u. or 1000 i.u. Scottish Blackface ewes received 1000 i.u. or 1500 i.u. The anaesthetic and surgical procedures for recovery of the sheep eggs have been described previously (Hancock \& Hovell, 1961). The solution used for recovery was Tyrode or Hanks solution containing $1 \mathrm{mg} / \mathrm{ml}$ bovine serum albumin with added streptomycin $(50 \mathrm{mg} / \mathrm{ml})$ and penicillin (50 i.u. $/ \mathrm{ml}$ ).

Unsuccessful attempts were made to remove the zona pellucida of the sheep eggs by treatment with pronase in Earles solution at various concentrations $(0.05 \%, 0.2 \%, 0.5 \%$ and $1.0 \%)$ using the procedure described by Mintz (1962). With the technique which was finally adopted, removal was effected manually by means of a micropipette (Tarkowski, 1959).

The zona-free eggs were placed in contact in a microdrop of medium at $37^{\circ} \mathrm{C}$. When the eggs were judged to be adhering they were transferred to the incubator and examined periodically during the next $24 \mathrm{hr}$. If the degree of fusion was sufficient for them to be handled without separation the pairs were transferred to recipient ewes on the day of recovery or on the following day. Eggs which separated during the culture period were transferred singly. Transfers were also made of intact eggs following culture for $48 \mathrm{hr}$ in vitro. The number of foetuses present in pregnant ewes which had received fused eggs was determined radiographically about 100 days after transfer.

Throughout the experiment the 1st day of oestrus is referred to as Day 0, and the sheep are referred to as Day 3,4 or 5 donors or recipients according to the interval between oestrus and operation.

The parentage of lambs born was determined by transferrin typing. The transferrin locus (Tf) of the sheep used in these experiments has five alleles, A, B, C, D and E, each of which modifies the electrophoretic mobility of the plasma (and serum) protein transferrin. The genotypes which result can be distinguished by inspection of the stained protein bands after electrophoresis in starch gel and named by comparison with reference sera. The notation used in this paper has been given recently elsewhere (Oosterlee \& Bouw, 1967).

Animals were bled by jugular puncture except for the stillborn lamb 7B32 from which blood was obtained by cardiac puncture. The serum was separated by centrifugation after 20 to $24 \mathrm{hr}$ at $18^{\circ} \mathrm{C}$ to $25^{\circ} \mathrm{C}$ and stored in $0.5-\mathrm{ml}$ to 1.0 -ml aliquots at $-15^{\circ} \mathrm{C}$ to $-18^{\circ} \mathrm{C}$. Samples for electrophoresis were warmed in a $56^{\circ} \mathrm{C}$ bath just long enough to thaw them; the unused portion was returned to the freezer within $5 \mathrm{~min}$. Samples frozen and thawed more than three times were discarded. For electrophoresis Poulik's modified buffer system was used.

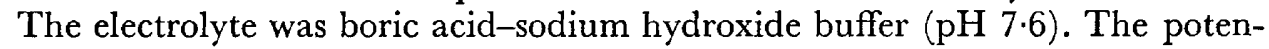


tial difference was 6 volts $/ \mathrm{cm}$ and the duration was sufficient to advance the forward edge of the albumen 9 to $10 \mathrm{~cm}$ from the origin. The gel was sliced horizontally, stained in $1 \%$ nigrosin and cleared in a mixture of methanol, water and glacial acetic acid (50:50:10 v/v).

\section{Mice}

\section{RESULTS}

Fusion was attempted in forty pairs of mouse eggs and twenty-six pairs were successfully fused. Blastocysts examined after fixing and staining were morphologically normal and active, judged by the presence of mitotic figures, and were obviously larger than blastocysts of the same age from single embryos. Clearly the culture medium adopted was adequate for the survival in vitro of mouse eggs for at least $48 \mathrm{hr}$.

Sheep

Transfer of intact eggs. Intact ova cultured for $48 \mathrm{hr}$ in vitro showed morphological evidence of degenerative changes; of twenty-two eggs transferred to fifteen ewes, none developed to term.

Removal of zona pellucida. Preliminary observations showed that the zona pellucida of the sheep egg was more resistant to pronase than was that of the mouse egg. With the highest concentration of enzyme the zona pellucida of the sheep egg was digested only after $1 \frac{1}{2} \mathrm{hr}$ treatment whereas that of the mouse egg treated in the same drop of medium was removed in less than 4 min.

Removal of the sheep zona pellucida by this prolonged enzyme treatment resulted in the separation of the blastomeres. For this reason it was decided to adopt the method of mechanical removal described by Tarkowski (1959). With this method it was difficult to remove the zonae pellucidae of 8- to 16-cellsheep eggs without the blastomeres separating or becoming damaged, but with 5-day morulae (16- to 32-cell) the method was successful. Five-day-old eggs were, therefore, chosen for fusion.

Transfer of eggs after removal of the zona pellucida. In view of the evidence of the onset of degeneration in intact eggs cultured for $48 \mathrm{hr}$, eggs were transferred either on the day of recovery or on the following day. Of eleven eggs transferred on the day of recovery, to six ewes, none developed to term (in two ewes return to service was delayed until 23 days and 27 days). Twenty-five eggs were transferred after culture for $24 \mathrm{hr}$ to thirteen recipients. Ten ewes returned to service, in one ewe return was delayed until 54 days. Three ewes lambed; each had received a Blackface $\times$ Blackface and Welsh $\times$ Dorset Horn egg. Of these three ewes, one gave birth to Blackface $\times$ Blackface and Welsh $\times$ Dorset Horn twins. The remaining two ewes were Welsh and they gave birth to single Welsh $\times$ Dorset Horn lambs, in these two cases the possibility that the lambs had developed from native eggs was excluded. Tf typing showed that both lambs were $\mathrm{AB}$ and both recipients were $\mathrm{DD}$.

Transfer of fused ova (zona pellucida removed). Transfers were made to twentytwo ewes of pairs of eggs which had been fused in vitro. Eight of these ewes received fused eggs which had been cultured for $24 \mathrm{hr}$ in vitro. Seven ewes returned to service within 18 days and one returned at 20 days. 
Fused eggs were transferred on the day of recovery to fourteen ewes. Nine ewes returned to service within 18 days and two returned at 38 days. Three Blackface ewes were shown to be carrying single lambs when examined radiographically and single lambs were born to these. Two of these had received fused pairs of Blackface eggs and the third had received a Blackface and a Welsh egg. All the lambs were of the Blackface type. It was possible by transferrin typing to exclude the existence of chimaerism as regards one lamb and no positive evidence of chimaerism could be found in a second. The third lamb was stillborn at 136 days. The serum of this lamb showed a unique transferrin pattern with three components having the mobility of types B, C and E (Plate 1). The transferrin types of the animals involved are shown in Table 1. The

TABLE 1

THE TRANSFERRIN TYPES OF PARENTS OF THE PUTATIVE CHIMAERIC LAMB 7B32

\begin{tabular}{c|c|c|c|c|c|c|c}
\hline \multicolumn{2}{c|}{ Recipient } & \multicolumn{2}{c|}{ Dam } & \multicolumn{2}{c|}{ Sire } & \multicolumn{2}{c}{ Progeny } \\
\hline Ewe & Tf type & Ewe & Type & Ram & Type & Lamb & Type \\
\hline 0A68 & CD & $\begin{array}{l}\text { 1T414 } \\
\text { 1A89 }\end{array}$ & $\begin{array}{c}\text { AB } \\
\text { CE }\end{array}$ & $\begin{array}{c}\text { 2S201 } \\
\text { 2S201 }\end{array}$ & $\begin{array}{c}\text { AC } \\
\text { AC }\end{array}$ & 7B32 & BCE \\
\hline
\end{tabular}

simplest Mendelian explanation of these findings is that the $\mathrm{C}$ band was contributed by the sire $2 \mathrm{~S} 201$ to both zygotes, that the B band came from donor ewe 1T414 and that the E band came from the second donor ewe 1A89.

\section{DISGUSSION}

It was realized at the start of these experiments that the slower cleavage rate of the sheep egg in vivo compared with that of the mouse virtually ruled out the possibility of inducing chimaerism in vitro so that chimaeric zygotes could be transferred to recipient ewes. However, it was hoped that the treatment used to obtain adhesion in vitro between eggs would not impair subsequent development; unfortunately this did not prove to be the case and it is clear that more information is needed about the cultural requirements of sheep eggs if the procedure is to be adopted with any hope of more than an isolated success.

The sheep eggs also presented unforeseen difficulties. Pronase removed the zona pellucida in these experiments only after prolonged exposure to the enzyme, resulting in subsequent separation of the blastomeres; Tarkowski's method of removal by mechanical means is obviously to be preferred in future experiments. The demonstration here that lambs will develop to term following transfer of eggs after removal of the zona pellucida shows that this procedure creates no special difficulties for subsequent development and there is every reason to believe that the induction of chimaerism will be as practicable in sheep as it is in mice.

The evidence for the successful induction of chimaerism reported here rests exclusively on the transferrin types of the parents and the lamb. However, other explanations for the presence of the unique pattern in the lamb must be 

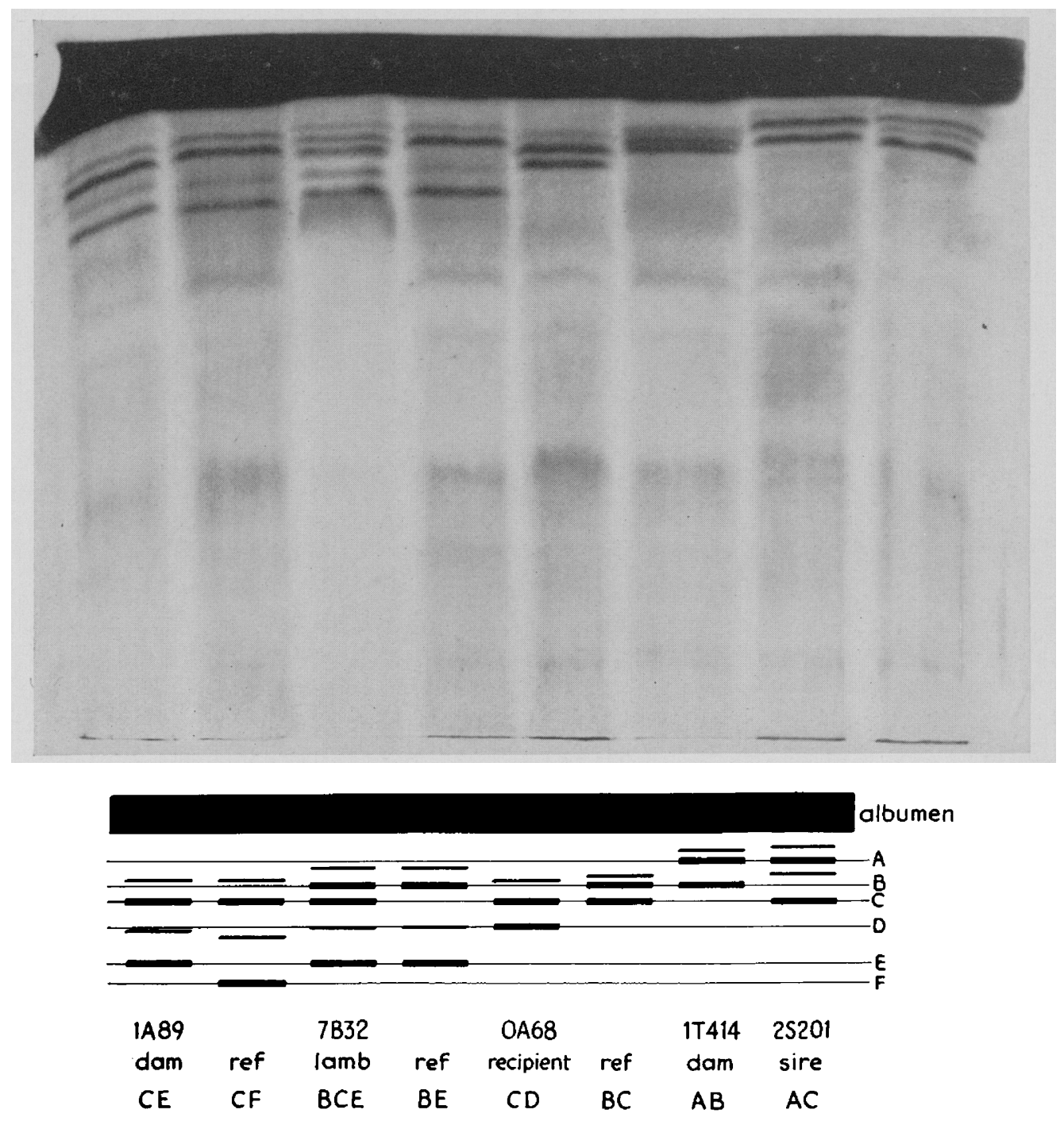

Photograph (and diagram) of starch-gel showing electrophoretic patterns of transferrins from putative chimaeric lamb 7B32 and related sheep. Patterns of three reference sera (ref) are also shown. 
carefully considered. First, the composite transferrin pattern may have been a simple mixture resulting from an anastomosis between twin foetuses one of which was lost as a result of an unobserved abortion. Such an event must have occurred before the 96th day when radiographic examination showed the presence of a single foetus. Information is lacking that transferrin acquired in this way might persist in high enough concentration to show so clearly in the stillborn lamb 40 days later. This possibility seems very unlikely in the light of general knowledge of the rate of fall in plasma concentration of passively acquired proteins. The second possibility is that transferrin-producing cells may have migrated through a vascular anastomosis from the hypothetical co-twin and settled down to produce their own type of transferrin. There is no specific evidence for sheep, but Jamieson (1965) has shown that cattle twins with erythrocyte chimaerism do not have transferrin chimaerism. The third possibility is not so easily rejected. The blood sample was taken from a stillborn lamb and the possibility of protein degradation sufficient to make a detectable change in the electrophoretic mobility of the transferrin molecules cannot be excluded.

The repeated sampling of individual animals having apparently unusual transferrin types, and of their relatives is regarded by the authors as an essential safeguard against misleading observations (see Lush, 1966). The nature of the material prevented this extra precaution being carried out on this occasion. Mixtures of sera of standard transferrin types simulating the BCE pattern were prepared and gave closely similar electrophoretograms.

\section{REFERENCES}

Hancock, J. L. \& Hovell, G. J. R. (1961) Transfer of sheep ova. 7. Reprod. Fert. 2, 295.

JAmieson, A. (1965) The genetics of transferrins in cattle. Heredity, Lond. 20, 419.

Lush, I. E. (1966) The biochemical genetics of vertebrates except man, p. 63 . North Holland, Amsterdam.

MiNTz, B. (1962) Experimental study of the developing mammalian egg: removal of the zona pellucida. Science, N.Y. 138, 594.

MrNTz, B. (1964) Formation of genetically mosaic mouse embryos and early development of 'Lethal $\left(\mathrm{t}^{12} / \mathrm{t}^{12}\right)$-Normal' mosaics. F. exp. Zool. 157, 273.

OosterleE, C. G. \& Bouw, T. (1967) Nomenclature of transferrin types in sheep. Immunogenet. Lett. 5 10.

TARKowsKI, A. K. (1959) Experimental studies on the development of isolated blastomeres of mouse eggs. Acta theriol. 3, 191.

TArkowski, A. K. (1961) Mouse chimaeras developed from fused eggs. Nature, Lond. 190, 857. 